\title{
Stem cells in spinal cord injury
}

\author{
Jean R. Wrathall* and Judith M. Lytle \\ Department of Neuroscience, Georgetown University Medical Center, Washington, DC 20057, USA
}

\begin{abstract}
Traumatic injury to the adult spinal cord results in a massive loss of cells and permanent functional deficits. However, recent studies demonstrate that there is a proliferative response of endogenous glial precursors and progenitors and perhaps also pluripotent neural stem cells. These cells may prove to be an important new therapeutic target to improve recovery after injury to the spinal cord and brain.
\end{abstract}

Keywords: Neural stem cells, oligodendrocyte precursor cells, $\mathrm{NG}^{+}$cells

\section{Introduction}

Spinal cord injury (SCI) causes loss of local segmental neurons, axons that pass through the site of injury, and local glial cells that are needed for the continued survival and normal function of remaining neuronal elements. In most mammalian species, even a relatively mild bruising of the spinal cord results in the formation of a central cavity that is devoid of neuronal elements. Permanent functional deficits are due to loss of local neuronal networks at the injury site as well as the interruption of axonal pathways carrying sensory information to the brain and of descending motor control pathways to the spinal cord distal to the injury site. Investigators have attempted to replace the lost tissue and reconstruct the injured spinal cord with a variety of tissue transplants and transplanted cells [62,99,116, 135]. The most recent experiments have utilized stem cells including pluripotent or pre-differentiated embryonic stem cells, embryonic or adult neural stem cells and bone marrow derived stem cells $[42,79,90]$. Other investigators have focused on the response of endogenous adult spinal cord stem and progenitor cells to SCI, as described below. Both avenues of investigation have demonstrated the difficulty of achieving substantial neurogenesis in the injured adult spinal cord.

* Corresponding author: Jean R. Wrathall, Ph.D., Department of Neuroscience, Georgetown University Medical Center, 3970 Reservoir Rd., N.W., Washington, DC 20057, USA. Tel.: +1 202687 1196; Fax: +1 202687 0617; E-mail: wrathalj@georgetown.edu.
On the other hand, significant improvement in recovery after SCI can occur when gliogenesis, specifically the generation of new oligodendrocytes, is increased after SCI through the transplantation of glial restricted stem cells or oligodendrocyte precursor cells (OPCs) [3,23, 89]. Alternatively, it may be possible to stimulate endogenous adult OPCs to improve recovery after SCI.

This review will focus on the recent evidence that endogenous glial stem/progenitor/precursor cells are naturally stimulated to proliferate after traumatic spinal cord injury, recapitulate some aspect of normal development and contribute to the limited recovery of function that is seen. We will also consider the potential for enhancing this response and the possibility that cells with greater pluripotency, true neural stem cells, may be at least transiently activated by SCI.

\section{Cell loss after SCI}

The adult spinal cord is composed of a number of cell types. Some, for example the endothelial cells lining blood vessels, are similar (though not identical) to those found throughout the body. Some cell types are restricted to nervous tissue, such as neurons, and others are only found in the central nervous system (CNS). Classically, the latter include the ependymal cells that line the central canal of the spinal cord (and the ventricles of the brain) and supporting cells present throughout the tissue parenchyma that are termed neuroglia. These include astrocytes that function to regulate the 
ionic microenvironment surrounding the neurons and oligodendrocytes that myelinate axons in the CNS. In addition, as discussed further below, there are now believed to be significant numbers of non-neuronal cells in the adult CNS expressing the NG2 proteoglycan that may serve a variety of functions, including acting as glial progenitor cells.

The cells of the adult spinal cord not only interact metabolically and functionally but also via complex interdigitating cellular processes. Furthermore, the spinal cord is arranged with a central core of gray matter containing the local neuronal networks innervating each rostro-caudal segment of the body surrounded by white matter containing longitudinally arranged axons connecting these local networks to those above and below, as well as long tracts of axons conveying information to the brain and receiving directions from supraspinal centers. This anatomical organization means that a restricted injury to even one segment of the spinal cord results not only in local segmental loss of innervation but also causes loss of sensory perception and loss of motor function (paralysis) in all distal segments of the spinal cord.

In addition, an initial mechanical injury to the spinal cord initiates a series of "secondary injury" processes $[8,48]$ such that even a relatively mild bruise (contusion) of the spinal cord can results in massive cell loss and typically in the formation of a central cavity devoid of neurons or glial cells that persists chronically after SCI [88].

\section{Transplantation approaches to reconstruct the injured spinal cord}

Given the massive cell loss at the injury site from even mild traumatic injury and the absence of spontaneous healing, there has been a long history of experimental transplantation of embryonic and/or adult nervous tissue used in attempts to "reconstruct" the injured spinal cord $[62,116,135]$. Key advances have been made with this approach. It has been convincingly demonstrated (1) that adult CNS neurons are capable of axonal regeneration when provided with a suitable environment, such as that provided by a peripheral nerve graft [14], (2) that there are specific myelin-associated inhibitors of axonal regeneration [24] in the adult spinal cord (and brain) and that this inhibition can be experimentally reduced with specific strategies [16] and (3) that regenerative potential can be increased with ex- ogenous neurotrophic factors [61,94], with combined strategies being the most effective $[15,78,92]$.

The recent explosion of knowledge about both embryonic stem cells and the presence of a neural stem cell pool in regions of the adult mammalian brain, has led to a number of studies in which embryonic or adult stem cells were transplanted into the injured spinal cord $[42,79,90]$. Initial results showed no functional benefits with the stem cells differentiating exclusively into astrocytes. More recently, stem cells that were partially pre-differentiated in tissue culture were used and oligodendrocytes, and in some cases even new neurons, appeared to be formed after transplantation into the injured spinal cord $[63,89]$. Interestingly, when improved function has been observed after stem cell transplantation it appeared likely that it was due largely to improved myelination of original axons that survived SCI [54,57].

\section{Endogenous stem/progenitor cells in the spinal cord}

If stem cells, particularly glial stem/progenitor cells, are beneficial for recovery after SCI, are such cells already present in the adult spinal cord? Do they survive SCI? Do they proliferate in response to traumatic injury and play a role on the partial functional recovery often seen after SCI? To answer such question one needs to know the characteristics by which neural and glial stem/ progenitors cells in the injured adult spinal cord can be identified.

During embryonic development of the spinal cord, as in other parts of the CNS, pluripotent neural stem cell cells arise from cells of the primitive neural tube. As shown in Fig. 1, these neural stem cells express specific transcription factors, including SOX1 and SOX2, as well as the intermediate filament protein, nestin [69]. Several recent papers argue that SOX2 is the best antigenic marker for these cells and is key to defining them as neural stem cells $[33,45,93]$. When SOX2 expression is down-regulated these cells enter either the neuronal or glial precursor cells lineage [45]. The former begin to express neuron-specific antigens and the latter then begin to express antigenic markers of the oligodendrocyte or astrocyte lineages. Figure 1 illustrates a current view of the developmental progression of stem cells, progenitors, and committed precursors in the formation of mature neurons and the glia in the in the spinal cord. The NG2+ cell is just one type of progenitor cell that arises from Sox2-expressing stem cells but it has been the most extensively studied, as summarized below. 


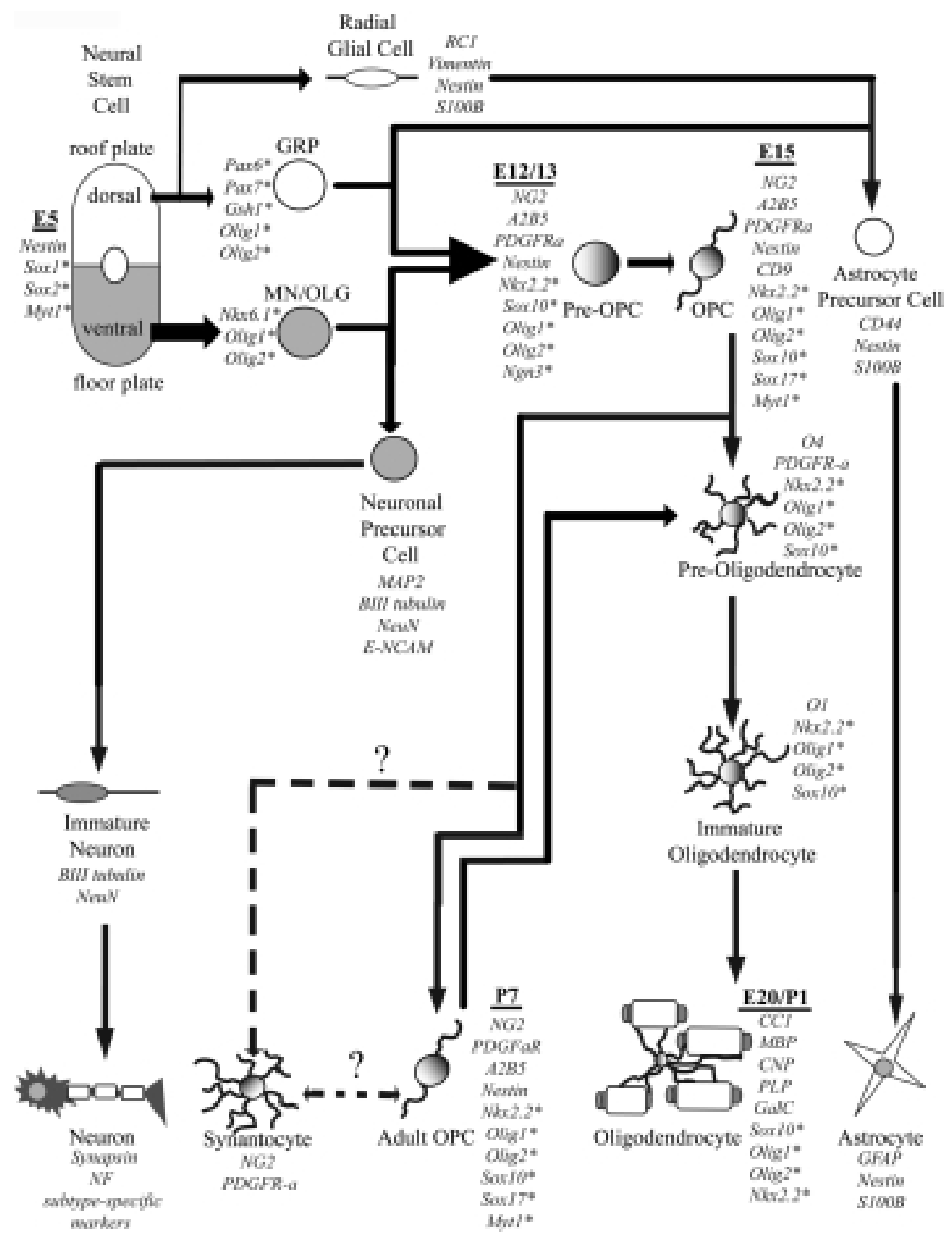

Fig. 1. Stem cells, progenitors and precursor cells involved in development of the mature cells of the spinal cord. Characteristic marker antigens, including transcription factors $(*)$ are indicated for each cell type. Postulated origins from the roof and floor plates of the neural tube are indicated as well as postulated lineage relationships. The size of arrows on embryonic day 5 (E5) indicates relative contribution to the different lineages, as noted in the text. The origin of synantocytes and lineage relationship with oligodendrocyte lineage cells is unknown, as indicated by (?). This schema is based on published studies by a number of investigators $[1,20-22,25,37,69,76,106,107,118,120,122]$. GRP $=$ glial restricted precursor; $\mathrm{MN} / \mathrm{OLG}=$ motor neuron/oligodendrocyte progenitor; $\mathrm{OPC}=$ oligodendrocyte progenitor cell.

\section{NG2+ cells in the developing spinal cord}

For immunohistochemical studies of tissue, the most useful marker of oligodendrocyte precursor cells (OPCs) during development is surface expression of the NG2 proteoglycan (for review, see [109]). NG2 is a chondroitin sulfate proteoglycan that binds with high affinity to the growth factors basic fibroblast growth factor (bFGF) and platelet derived growth factor $(\mathrm{PDGF} \alpha \mathrm{R})$ [44], which are critical mitogens for 
oligodendrocyte precursor cells (OPCs) $[4,13]$. It has been suggested that NG2 may potentiate growth factor effects by assembling them at the cell surface and presenting them to their respective receptors [109]. Furthermore, NG2 interacts with the cytoskeleton [66,67], which is necessary for NG2-mediated migration [35]. NG2 also acts as a mediator in transmembrane signaling, including activation of small GTPases [85-87, 101], which interact with $\mathrm{p} 21$-activated kinases to initiate downstream signaling cascades involved in motility and alterations in morphology [73,105].

A great deal is already known about the proliferation and maturation of $\mathrm{NG} 2+$ oligodendrocyte progenitor cells in the developing spinal cord. During embryonic development, the neuroepithelial stem cell gives rise to multiple types of progenitor and precursor cells from restricted areas of the spinal cord. As depicted in Fig. 1, the ventral pMN domain gives rise to a motor neuron/oligodendrocyte precursor cell, from which 85$90 \%$ of mature oligodendrocytes arise [39]. A dorsal pool of glial restricted precursors (GRPs) from the dorsal domains $\mathrm{dP} 3-\mathrm{dP} 5$, gives rise to the remaining 10 $15 \%$ of oligodendrocytes, although these OPCs arise two days after the ventral pool $[22,25,37,76,120]$. This pattern of oligodendrocyte development is similar to what occurs in the developing brain, specifically in the telencephalon [58] where ventral regions give rise to the first pool of OPCs which then migrate dorsally and dorsal regions then give rise to another wave of OPCs, which migrate ventrally.

In the rodent spinal cord, NG2 expression first occurs in OPCs at approximately embryonic day 12-13, and ultimately gives rise to mature, myelinating oligodendrocytes (For review, see [69]). During spinal cord development, all cells that express the NG2 proteoglycan are regarded as embryonic OPCs $[69,82]$, small undifferentiated cells that express PDGF $\alpha \mathrm{R}$ [82]. In vitro, these cells also express A2B5 [1], and go on to express the $\mathrm{O} 4$ and $\mathrm{O} 1$ antigens $[107,118]$ and galactocerebrocide (GalC, a mature oligodendrocyte marker), suggesting that $\mathrm{NG}_{2}{ }^{+}$cells in the developing animal are OPCs [49]. In medium containing high serum content, these cells develop into type 2 astrocytes [97]. Therefore, $\mathrm{NG}_{2}{ }^{+}$cells are often referred to as $\mathrm{O}-2 \mathrm{~A}$, or oligodendrocyte-type 2 astrocyte progenitors. However, it is not known whether embryonic NG2+ cells give rise to astrocytes in vivo.

Transcription factor expression is correlated with maturation of $\mathrm{NG}_{2}{ }^{+} \mathrm{OPCs}$ during embryonic development. As shown in Fig. 1, many transcription factors are expressed at specific timepoints of lineage progres- sion, and each has an important role in lineage specification and maturation. Dorsally and ventrally-derived OPC pools express specific transcription factors in the pre-OPC stage (Fig. 1), but OPCs from both ventral and dorsal pools acquire Olig1, Olig2 and Nkx2.2 expression before progressing along the oligodendrocyte lineage $[39,59,68,95,112,125,132,133]$. Knockout studies reveal that these transcription factors are necessary for lineage progression and/or (re)myelination, as summarized below.

While Olig1 is necessary for differentiation of early oligodendrocyte lineage cells, Olig2 is required for the formation of $\mathrm{O}_{4}^{+}$pre-myelinating oligodendrocytes during development, as shown in the cortices of Olig2 ablated mice [129] as well as in in vitro studies where antisense oligonucleotides are used to inhibit expression [39]. Olig $2^{-/-}$mice have no oligodendrocytes in the spinal cord [111], with no effect in the hindbrain $[131,133]$. Olig1/2 double knockouts result in elimination of motor neurons and a complete lack of mature oligodendrocytes [131,133].

In addition to Olig2, Nkx2.2 expression is necessary for OPCs to differentiate into mature, MBP-expressing oligodendrocytes [39,95,132]. Mutation of the Nkx2.2 gene causes a dramatic reduction in MBP and PLP expression [95]. Nkx2.2 $2^{-/-}$mice have no mature oligodendrocytes in the spinal cord [68]. Knocking out either Olig1/Olig2 or Nkx2.2 does not affect expression of Nkx2.2 or Olig1/Olig2, respectively.

During the early postnatal period, there is extensive proliferation of NG2+ cells in the spinal cord. As differentiation and myelination proceeds, the proliferation of NG2+ cells in the spinal cord tapers off. However, many NG2 + cells remain present in the normal adult spinal cord [52].

\section{NG2 + cells in the normal adult spinal cord}

Bromodeoxyuridine (BrdU) incorporation studies have shown that mitotic NG2 ${ }^{+}$cells are the major population of dividing cells in the mature CNS [28,51], and have generally been referred to as AOPCs. Both OPCs and AOPCs can differentiate into mature oligodendrocytes and astrocytes in vitro [122]. However, AOPCs do not express CD-9, a protein expressed on the cell surface of OPCs involved in motility [115]. Additionally, studies done in the optic nerve reveal functional differences between AOPCs and their perinatal counterparts: 1) OPCs undergo quick, symmetrical division ( $\sim 18 \mathrm{hr}$ ), while AOPCs are slow and divide asymmet- 
rically ( $\sim 65 \mathrm{hr}$ ), 2) OPCs differentiate in less than 3 days, compared to a minimum of 5 days for AOPCs, and 3) OPCs migrate more quickly $(21 \mu \mathrm{m} / \mathrm{hr})$ than AOPCs $(4 \mu \mathrm{m} / \mathrm{hr})$ [122]. Similar rates have been reported in spinal cord NG2 ${ }^{+}$cells [51]. It has been suggested that AOPCs are likely to be a mixed population containing multiple glial progenitor phenotypes, possibly including an astrocyte precursor cell population or a common glial progenitor $[43,81]$.

Although spinal cord NG2+ cells during development are recognized as OPCs, the $\mathrm{NG}_{2}{ }^{+}$cell population in the adult appears to be heterogenous, and is likely to be comprised of multiple cell types. $\mathrm{NG} 2^{+}$ glia in the adult CNS have been collectively referred to as "polydendrocytes", which include, but are not restricted to, the adult OPC (AOPC) population [83]. The NG2+ "synantocyte", a polydendrocyte subset, has been described as a morphologically complex, mature, specialized cell [10]. $\mathrm{NG} 2^{+}$cells that express platelet derived growth factor receptor $\alpha$ (PDGF $\alpha \mathrm{R})$ have generally been considered AOPCs in the adult CNS [27, 100]. However, synantocytes express PDGF $\alpha \mathrm{R}$, making the distinction between the AOPC and synantocyte subpopulations of polydendrocytes difficult. The synantocytes described in vivo may be equivalent to the in vitro type- 2 astrocyte that arises from $\mathrm{NG} 2{ }^{+} \mathrm{A} 2 \mathrm{~B} 5^{+}$ cells $[10,36,40]$. In vivo, however, synantocytes are functionally distinct from astrocytes; They do not express astrocyte markers such as the intermediate filaments glial fibrillary acidic protein (GFAP), vimentin, the calcium-binding protein S-100 $\beta$, or glutamine synthetase (GS, involved in conversion of glutamate to glutamine) $[19,65,83,100]$. The lack of intermediate filaments likely discounts synantocytes as functioning in physical support. Synantocytes and astrocytes both contact nodes of Ranvier and synapses [18,119], but astrocytes also form the glial limitans [18], whereas synantocyte processes do not $[18,91]$. Also, synantocytes are not dye-coupled through gap junctions [9]. Therefore, it is unlikely that synantocytes are an astrocytic population.

\section{Proliferation of NG2 + cells after SCI}

$\mathrm{NG}^{+}$cells undergo division in response to different types of insult, including contusive SCI [50,53,56,64, $72,75,98,130]$. A rat model of contusive SCI shows that $\mathrm{NG}^{+}$cells proliferate after injury and that this proliferation is greatest 3 days after injury [130]. A BrdU pulse at this time-point results in many BrdU- labeled oligodendrocytes chronically, and oligodendrocyte density in the spared white matter is not different from uninjured controls at 6 weeks after injury in the rat [103], suggesting that progenitor cells that divide in the acute injury phase have the ability to differentiate to repopulate the injured spinal cord to replace mature glia $[50,75,130]$. Furthermore, evidence for cell proliferation and replacement of mature oligodendrocytes and astrocytes has recently also been seen after SCI in a primate model [126].

$\mathrm{NG}^{+}$cell density in the injured spinal cord remains elevated for at many weeks after injury [75,103,130]. However, relatively little has been published on the identification of distinct sub-populations of $\mathrm{NG}_{2}{ }^{+}$cells and their potential contributions in SCI. After transection of the anterior medullary velum, synantocytes, as identified by NG2 immunoreactivity and complex secondary and/or tertiary branching, undergo morphological transformation, proliferate, and migrate [21,53,64, 84,91]. NG2 ${ }^{+}$synantocytes contribute to the formation a protective glial scar in response to CNS injury [21], a function generally attributed to astrocytes [32]. This response, however, has not been specifically observed in SCI. The role of synantocytes after SCI has not been elucidated.

The question remains as to whether NG2-expressing glia in the injured spinal cord are comprised of multiple populations with differential responses to injury; whether the NG2 pool contains OPCs, synantocytes, and/or other types of reactive or nascent cells, and what the developmental potential and lineage relations are among these cell types. The use of mouse injury models in which progenitor cells are genetically marked $[26,55]$ and/or can be followed by fate mapping techniques $[63,134]$ would be advantageous for studies of the endogenous stem/progenitor cell response to SCI.

However, some aspects of SCI in the mouse $[6,60$, $104,108]$ differ from that in rats, cats, and primates [7, $12,88,108,113]$. We therefore used a mouse version of our contusion injury model [60] to study cell loss, proliferation and replacement of glia after SCI in C57B1/6 mice [72]. The results showed that, in addition to complete loss of gray and white matter in the lesion per se, the density of mature oligodendrocytes and astrocytes in spared white matter at the epicenter decreased significantly by $24 \mathrm{~h}$ after injury to about $50 \%$ of that in normal uninjured mice by 7 days after injury. $\mathrm{NG}^{+}$cell density also initially decreased at $24 \mathrm{~h}$, then increased so that by $7 \mathrm{dpi}$ it was more than twice that in normal uninjured white matter. In order to further define the $\mathrm{NG}_{2}{ }^{+}$ 
cell population, we quantified $\mathrm{NG} 2{ }^{+} / \mathrm{Cd} 11 \mathrm{~b}^{-}$cells (as some $\mathrm{Cd} 11 \mathrm{~b}+$ macrophages/microglia transiently express $\mathrm{NG} 2$ after $\mathrm{SCI}$ ), as well as $\mathrm{NG}_{2}{ }^{+} /$nestin $^{+}$cells. The results indicate that that most NG2 cells in the residual ventral white matter did not express $\mathrm{Cd} 11 \mathrm{~b}$. Some $25-50 \%$ of $\mathrm{NG}^{+}$cells were also immunopositive for nestin, another progenitor cell marker, depending upon time after injury and distance from epicenter.

To determine whether the increased densities of some cell types was due to stimulation of cell proliferation occurring after injury we injected bromodeoxyuridine (BrdU), which labels proliferative cells in S-phase, during the 6 hours prior to perfusing the mice, at various times after injury . BrdU labeling was rarely observed in white matter of uninjured controls and very little in residual white matter at one day after SCI. However on days 3 and 7 , many $\mathrm{BrdU}^{+}$nuclei were detected, including those of cells that expressed NG2 or Cd11b both in preserved white matter at the epicenter and in tissue at several $\mathrm{mm}$ distal to it. Maximal BrdU incorporation in $\mathrm{NG}_{2}{ }^{+}$cells occurred at 3 days after injury and in tissue rostral to the injury epicenter. When we performed double-labeling of cells that incorporated BrdU using antibodies against NG2 for progenitors and $\mathrm{Cd} 11 \mathrm{~b}$ for microglia/macrophages we found that $\mathrm{NG}^{+}$cells comprised $20-55 \%$ of BrdU-labled cells, depending upon location and time after injury with the peak at 3 days and at $1.5 \mathrm{~mm}$ rostral to the injury epicenter. The peak of $\mathrm{Cd} 11 \mathrm{~b}^{+}$proliferation was observed at the injury epicenter at 7 days after injury.

The chronically injured C57BL6 mouse spinal cord was then examined for distribution of cells that incorporated BrdU on days 2-4 after injury and survived to 28 days. Double labeling was performed to determine if these cells became mature oligodendrocytes $(\mathrm{CC} 1+)$, mature astrocytes $(\mathrm{GFAP}+)$, or remained $\mathrm{NG} 2+$ cells or microglia/macrophages $(\mathrm{Cd} 11 \mathrm{~b}+) \mathrm{We}$ observed many $\mathrm{CC} 1+\mathrm{BrdU}^{+}$oligodendrocytes and $\mathrm{GFAP}+\mathrm{BrdU}^{+}$astrocytes as well as $\mathrm{NG}^{+} \mathrm{BrdU}^{+}$ cells in the spared white matter. In addition, there was a small proportion of $\mathrm{Cd} 11 \mathrm{~b}^{+}$cells and these cells were occasionally $\mathrm{BrdU}^{+}$.

The observed glial cell loss and $\mathrm{NG}_{2}{ }^{+}$cell response in the $\mathrm{C} 57 \mathrm{Bl} / 6$ mouse is consistent with what has been reported in rats $[2,7,8,46,75,96,103,130]$. Thus, mouse models, in which specific cell types are marked by the expression of a transgene such as enhanced green fluorescent protein (EGFP) may be used to further study the endogenous glial and precursor/progenitor cell response to SCI.

The difference we observed in the total numbers of $\mathrm{NG} 2+$ cells and of $\mathrm{NG} 2+$ /nestin + cells may reflect multiple types of NG2 + cells with differential responses to injury. It has been estimated that less than $1 \%$ of all $\mathrm{NG} 2+$ cells in the normal adult are truly AOPCs [115] and results from a recent study of $\mathrm{NG} 2+$ cells in tissue cultures from the injured rats spinal cord indicated that not all NG2 + cells can be accounted for by the oligodendrocyte lineage markers A2B5, O4, and $\mathrm{O} 1$ [71]. Furthermore, as discussed above, it has been postulated that the $\mathrm{NG} 2+$ population in the adult is heterogeneous and consists of several cell types [83], including the synantocyte, which functions at nodes of Ranvier and at synapses [20]. These interactions could influence their proliferative response after injury [5,31]. Taken together, our working hypothesis is that the injured spinal cord contains several types of glial cells that are capable of responding to injury, including $\mathrm{NG} 2+\mathrm{OPCs}$ and NG2+ cells that are not in the oligodendrocyte lineage.

To test this hypothesis we are currently collaborating with Dr. Vittorio Gallo and using a transgenic mouse developed in his laboratory in which enhanced green fluorescent protein (EGFP) is expressed under the control of the 2'- 3'-cyclic nucleotide 3'-phosphodiesterase (CNP) promoter [128]. This allows for visualization of the entire oligodendrocyte lineage, including progenitors. Results from our recent study with these CNPEGFP mice [70] show that BrdU incorporation after SCI is stimulated both in CNP-EGFP+/NG2+ cells of the oligodendrocyte lineage as well as CNP-EGFP/NG2 + cells that may belong to a second population of non-OPC NG2 + cells present in the adult spinal cord. We are examining specific transcription factors necessary for embryonic OPCs to become mature oligodendrocytes $[68,95,131,133]$, and other proteins expressed by the NG2+ cells in the injured spinal cord to further distinguish the two populations. Interestingly, the temporal-spatial pattern of proliferation and transcription factor expression of the EGFP+ and EGFP- NG2+ cells seems to be distinct, suggesting they are different populations of precursor/progenitor cells stimulated by different environmental cues in the spinal cord after injury.

\section{Evidence for the response of endogenous progenitor cells and neural stem cells in the injured adult spinal cord}

The EGFP + NG2+ cells stimulated by SCI in the CNP-EGFP mouse are presumably OPCs, that is, progenitor cells committed to the oligodendrocyte lineage. 
The nature of the EGFP ${ }^{-} \mathrm{NG}^{+}$cells is currently unclear. They do not consistently express markers of astrocyte precursors [70] so they may be glial progenitor cells that can give rise to both astrocytes and synantocytes and possibly also to cells that enter the oligodendrocyte lineage, in which case they would begin to express CNP and thus EGFP. Chronically after SCI in both the rat and mouse $[71,103]$ the density of astrocytes and NG2+ cells in spared tissue is even higher than normal despite their significant initial loss after injury. Further, as stated above, BrdU-labeled astrocytes and NG2 + cells, as well as BrdU-labeled mature oligodendrocytes are observed chronically if animals are injected with BrdU during the first week after injury. Thus, the response to SCI of endogenous progenitor cell type(s) that can produce two or more mature glial cell types appears to be likely. This is consistent with what is observed during embryonic development when, as depicted in Fig. 1, the Sox $2+$ Sox $1+$ nestin + neuroepithelial stem cell gives rise to multipotent progenitors, specifically a glial-restricted progenitor dorsally and an oligodendrocyte/motor neuron progenitor ventrally. Further, results from BrdU-labeling studies demonstrate that the normal adult rodent spinal cord continues to contain a pool of progenitor cells [51]. Indeed, the progenitor cell yield of the lumbosacral spinal cord, as assayed by multipotency in culture, has been estimated to be similar to that from the lateral ventricle [121]. Taken together, the current evidence strongly suggests that there is a pool of normal glial progenitors in the adult spinal cord that appear to be stimulated by SCI.

The question remains, does SCI in the adult spinal cord stimulate endogenous pluripotent neural stem cells as well as the glial precursor/progenitor populations we have discussed. One established way to look for stem cell potential is to use "neurosphere" culture methods to determine whether putative progenitor cells are capable of self renewal and whether they are multipotent, that is, able to differentiate along multiple cell lineages. Cells cultured from the normal adult spinal cord can express neuronal markers when grown under the right experimental conditions, or when transplanted into neurogenic regions of the brain $[38,41,114]$. Thus, although the adult spinal cord is not a neurogenic region of the CNS, cells with neurogenic potential are present. Are such endogenous stem cells stimulated by SCI?

In addition to studies in vivo, we have recently used a clonal neurosphere culture approach to probe the potential of NG2 + cells from the injured spinal cord [127].
We found not only are there more NG2 + cells in cell suspensions generated from the injured spinal cord but also that they produced more and larger "neurospheres". To test differentiation potential, the spheres were transferred to coated dishes to which they adhere and cultured with media that stimulated differentiation. We frequently saw oligodendrocytes differentiated from these clonally derived spheres. Less frequently they produced both oligodendrocytes and astrocytes, demonstrating at least some of the cells have bipotential glial progenitor potential. In addition, we have recently found that a least some spheres contain a high density of cells expressing both nestin and the SOX2 protein (Yoo and Wrathall, unplublished), markers that characterize pluripotent embryonic neural stem cells. Further, SOX-2 immunoreactivity can also be detected in vivo in the injured spinal cord and appears to be up-regulated in ependymal cells of the central canal in the first week after SCI (Wrathall, unpublished).

After SCI, in addition to proliferation of NG2+ cells in the spared tissue, several investigators have noted cell division in or near the central canal $[7,50,80,110]$. This structure is similar anatomically to the embryonic neural tube from which neural stem cells are derived during development. It is also continuous with the ventricular system of the brain, portions of which continue to be neurogenic in the adult [34]. The ependymal cell proliferation seen after SCI has been associated with the formation of astrocytes [77]. However, one recent study based on performing spinal cord injury on nestinlacZ transgenic mice reports that NeuN positive cells are formed from dividing ependymal cells [55], suggesting at least a transient attempt at neurogenesis. If ependymal cells that proliferate after SCI are SOX2+, it supports the concept that a there is also an endogenous neural stem cell response to SCI in addition to that of endogenous glial progenitors and OPCs.

Figure 2 summarizes our current view of the endogenous precursor, progenitor and stem cell response to SCI as deduced from studies on adult rats and mice after a contusion injury of the thoracic spinal cord.

\section{Endogenous stem/progenitor cells and improving recovery after SCI}

Although significant replacement of glial cells appears to occur naturally after SCI, many axons in the residual white matter are unmyelinated or abnormally myelinated chronically after experimental SCI [11, $117,124]$, suggesting that natural oligodendrocyte re- 


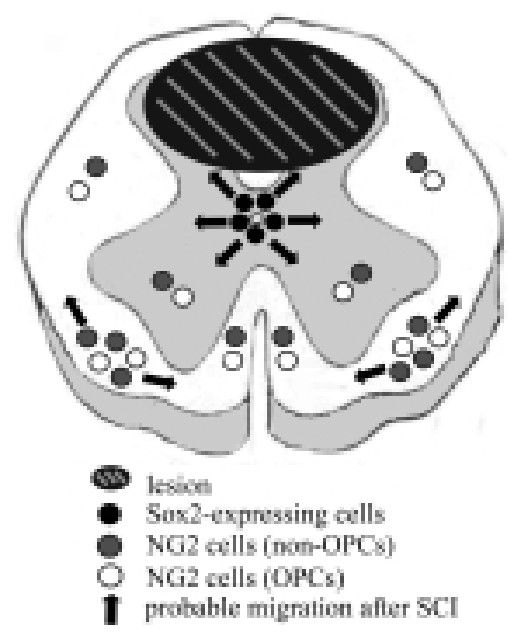

Fig. 2. Proliferation of stem cells, glial progenitors and oligodendrocyte precursor cells after contusive spinal cord injury. In tissue adjacent to the injury epicenter (the tapering distal portion of the lesion is shown dorsally), three putatively different cell types proliferate. A neural stem cells type, as indicated by expression of SOX2, appears to arise from cells of or near the ependyma of the central canal. Based on recent mouse studies [70], both OPCs and a non-OPC NG2+ cells are present throughout the parenchyma, and proliferate, especially in the ventrolateral white matter [72]. This cartoon is based on our own studies and those of other investigators $[50,72,75,80,130]$.

placement may be quantitatively and/or qualitatively suboptimal. Indeed, we have reported that an acute treatment that has no effect on acute axonal loss but spares oligodendrocytes, significantly enhances hind limb function after a standardized thoracic SCI [102, 123]. Furthermore, demyelination and abnormal remyelination, have also been observed chronically and linked to functional deficits in humans after SCI [17,29, 30,47,74]. Similarly, the persistent "reactive" phenotype of astrocytes chronically after SCI, suggests that although their numbers may be normalized (or greater than normal), their functioning is not. If the response of endogenous stem/precursor cells to SCI could be enhanced to result in the replacement of more glia and/or glia that functioned more normally, recovery after incomplete SCI would likely be improved. Enough is known about growth factors that stimulate the proliferation and differentiation of glial progenitors to experiment with whether this approach has therapeutic potential for spinal cord injury.

The replacement of lost neurons is more problematic as the appropriate function of many require growth of long axonal processes to distant targets and, as discussed earlier, the adult spinal cord contain inhibitors of such axonal growth. However, small interneurons that act locally in segmental networks are lost in SCI as well as the large neurons with long axons. The former are the sort of neurons that are replaced in the neurogenic regions of the adult brain - small local inhibitory interneurons. Perhaps, if we could induce endogenous neural stem cells to proliferate and differentiate into such interneurons, they could contribute to improved functional recovery after SCI.

\section{Conclusions}

Spinal cord injury is devastating because so many cells and their widespread connections are lost even after a mild traumatic injury, and the natural replacement of these cells and their essential connections is insufficient. Nevertheless, there is recent evidence in clinically relevant rodent models of SCI that there is extensive proliferation of glial precursor and progenitor cells and perhaps proliferation of neural stem cells. In the future, as we learn how to manipulate adult stem and progenitor cells, it may be possible to therapeutically enhance the response of the endogenous cells to increase functional recovery after injury.

\section{Acknowledgements}

Studies in our laboratory on stem/progenitor cells in SCI have been supported by NIH NINDS (R01 NS035647, T32 NS04128 and F31 NS051086), the Christopher Reeve and Sam Schmidt Foundations, and by the Paralyzed Veterans of America Research Foundation.

\section{References}

[1] E.R. Abney, B.P. Williams and M.C. Raff, Tracing the development of oligodendrocytes from precursor cells using monoclonal antibodies, fluorescence-activated cell sorting, and cell culture, Dev Biol 100 (1983), 166-171.

[2] A.A. Aguirre, R. Chittajallu, S. Belachew and V. Gallo, NG2expressing cells in the subventricular zone are type C-like cells and contribute to interneuron generation in the postnatal hippocampus, J Cell Biol 165 (2004), 575-589.

[3] N.C. Bambakidis and R.H. Miller, Transplantation of oligodendrocyte precursors and sonic hedgehog results in improved function and white matter sparing in the spinal cords of adult rats after contusion, Spine J 4 (2004), 16-26.

[4] W. Baron, B. Metz, R. Bansal, D. Hoekstra and H. de Vries, PDGF and FGF-2 signaling in oligodendrocyte progenitor cells: regulation of proliferation and differentiation by multiple intracellular signaling pathways, Mol Cell Neurosci 15 (2000), 314-329. 
[5] B.A. Barres and M.C. Raff, Proliferation of oligodendrocyte precursor cells depends on electrical activity in axons, Nature 361 (1993), 258-260.

[6] D.M. Basso, L.C. Fisher, A.J. Anderson, L.B. Jakeman, D.M. McTigue and P.G. Popovich, Basso Mouse Scale for locomotion detects differences in recovery after spinal cord injury in five common mouse strains, J Neurotrauma 23 (2006), 635-659.

[7] M.S. Beattie, J.C. Bresnahan, J. Komon, C.A. Tovar, M. Van Meter, D.K. Anderson, A.I. Faden, C.Y. Hsu, L.J. Noble, S. Salzman and W. Young, Endogenous repair after spinal cord contusion injuries in the rat, Exp Neurol 148 (1997), 453-463.

[8] M.S. Beattie, G.E. Hermann, R.C. Rogers and J.C. Bresnahan, Cell death in models of spinal cord injury, Prog Brain Res 137 (2002), 37-47.

[9] D.E. Bergles, A.V. Tzingounis and C.E. Jahr, Comparison of coupled and uncoupled currents during glutamate uptake by GLT-1 transporters, J Neurosci 22 (2002), 10153-10162.

[10] M. Berry, P. Hubbard and A.M. Butt, Cytology and lineage of NG2-positive glia, J Neurocytol 31 (2002), 457-467.

[11] A.R. Blight, Cellular morphology of chronic spinal cord injury in the cat: analysis of myelinated axons by linesampling, Neuroscience 10 (1983), 521-543.

[12] A.R. Blight and V. Decrescito, Morphometric analysis of experimental spinal cord injury in the cat: the relation of injury intensity to survival of myelinated axons, Neuroscience 19 (1986), 321-341.

[13] O. Bogler, D. Wren, S.C. Barnett, H. Land and M. Noble, Cooperation between two growth factors promotes extended self-renewal and inhibits differentiation of oligodendrocytetype-2 astrocyte (O-2A) progenitor cells, Proc Natl Acad Sci USA 87 (1990), 6368-6372.

[14] G.M. Bray, M.P. Villegas-Perez, M. Vidal-Sanz and A.J. Aguayo, The use of peripheral nerve grafts to enhance neuronal survival, promote growth and permit terminal reconnections in the central nervous system of adult rats, $J$ Exp Biol 132 (1987), 5-19.

[15] B.S. Bregman, J.V. Coumans, H.N. Dai, P.L. Kuhn, J. Lynskey, M. McAtee and F. Sandhu, Transplants and neurotrophic factors increase regeneration and recovery of function after spinal cord injury, Prog Brain Res 137 (2002), 257-273.

[16] A.D. Buchli and M.E. Schwab, Inhibition of Nogo: a key strategy to increase regeneration, plasticity and functional recovery of the lesioned central nervous system, Ann Med 37 (2005), 556-567.

[17] R.P. Bunge, W.R. Puckett, J.L. Becerra, A. Marcillo and R.M. Quencer, Observations on the pathology of human spinal cord injury. A review and classification of 22 new cases with details from a case of chronic cord compression with extensive focal demyelination, Adv Neurol 59 (1993), 75-89.

[18] A.M. Butt, A. Duncan and M. Berry, Astrocyte associations with nodes of Ranvier: ultrastructural analysis of HRP-filled astrocytes in the mouse optic nerve, J Neurocytol 23 (1994), 486-499.

[19] A.M. Butt, A. Duncan, M.F. Hornby, S.L. Kirvell, A. Hunter, J.M. Levine and M. Berry, Cells expressing the NG2 antigen contact nodes of Ranvier in adult CNS white matter, Glia 26 (1999), 84-91.

[20] A.M. Butt, N. Hamilton, P. Hubbard, M. Pugh and M. Ibrahim, Synantocytes: the fifth element, J Anat 207 (2005), 695-706.
[21] A.M. Butt, J. Kiff, P. Hubbard and M. Berry, Synantocytes: new functions for novel NG2 expressing glia, J Neurocytol 31 (2002), 551-565.

[22] J. Cai, Y. Qi, X. Hu, M. Tan, Z. Liu, J. Zhang, Q. Li, M. Sander and M. Qiu, Generation of oligodendrocyte precursor cells from mouse dorsal spinal cord independent of Nkx6 regulation and Shh signaling, Neuron 45 (2005), 41-53.

[23] Q. Cao, X.M. Xu, W.H. Devries, G.U. Enzmann, P. Ping, P. Tsoulfas, P.M. Wood, M.B. Bunge and S.R. Whittemore, Functional recovery in traumatic spinal cord injury after transplantation of multineurotrophin-expressing glialrestricted precursor cells, J Neurosci 25 (2005), 6947-6957.

[24] P. Caroni and M.E. Schwab, Oligodendrocyte- and myelinassociated inhibitors of neurite growth in the adult nervous system, Adv Neurol 61 (1993), 175-179.

[25] S. Chandran, H. Kato, D. Gerreli, A. Compston, C.N. Svendsen and N.D. Allen, FGF-dependent generation of oligodendrocytes by a hedgehog-independent pathway, Development 130 (2003), 6599-6609.

[26] T. Coksaygan, T. Magnus, J. Cai, M. Mughal, A. Lepore, H. Xue, I. Fischer and M.S. Rao, Neurogenesis in Talpha-1 tubulin transgenic mice during development and after injury, Exp Neurol 197 (2006), 475-485.

[27] M.R. Dawson, J.M. Levine and R. Reynolds, NG2expressing cells in the central nervous system: are they oligodendroglial progenitors? J Neurosci Res 61 (2000), 471-479.

[28] M.R. Dawson, A. Polito, J.M. Levine and R. Reynolds, NG2-expressing glial progenitor cells: an abundant and widespread population of cycling cells in the adult rat CNS, Mol Cell Neurosci 24 (2003), 476-488.

[29] M.R. Dimitrijevic, M.M. Dimitrijevic, J. Faganel and A.M. Sherwood, Suprasegmentally induced motor unit activity in paralyzed muscles of patients with established spinal cord injury, Ann Neurol 16 (1984), 216-221.

[30] M.R. Dimitrijevic, W.B. McKay and A.M. Sherwood, Motor control physiology below spinal cord injury: residual volitional control of motor units in paretic and paralyzed muscles, Adv Neurol 72 (1997), 335-345.

[31] N. Drojdahl, C. Fenger, H.H. Nielsen, T. Owens and B. Finsen, Dynamics of oligodendrocyte responses to anterograde axonal (Wallerian) and terminal degeneration in normal and TNF-transgenic mice, J Neurosci Res 75 (2004), 203-217.

[32] M. Eddleston and L. Mucke, Molecular profile of reactive astrocytes-implications for their role in neurologic disease, Neuroscience 54 (1993), 15-36.

[33] P. Ellis, B.M. Fagan, S.T. Magness, S. Hutton, O. Taranova, S. Hayashi, A. McMahon, M. Rao and L. Pevny, SOX2, a persistent marker for multipotential neural stem cells derived from embryonic stem cells, the embryo or the adult, Dev Neurosci 26 (2004), 148-165.

[34] J.G. Emsley, B.D. Mitchell, G. Kempermann and J.D. Macklis, Adult neurogenesis and repair of the adult CNS with neural progenitors, precursors, and stem cells, Prog Neurobiol 75 (2005), 321-341.

[35] X. Fang, M.A. Burg, D. Barritt, K. Dahlin-Huppe, A. Nishiyama and W.B. Stallcup, Cytoskeletal reorganization induced by engagement of the NG2 proteoglycan leads to cell spreading and migration, Mol Biol Cell 10 (1999), 33733387.

[36] C. Ffrench-Constant and M.C. Raff, Proliferating bipotential glial progenitor cells in adult rat optic nerve, Nature 319 (1986), 499-502. 
[37] M. Fogarty, W.D. Richardson and N. Kessaris, A subset of oligodendrocytes generated from radial glia in the dorsal spinal cord, Development 132 (2005), 1951-1959.

[38] J. Frisen, C.B. Johansson, C. Lothian and U. Lendahl, Central nervous system stem cells in the embryo and adult, Cell Mol Life Sci 54 (1998), 935-945.

[39] H. Fu, Y. Qi, M. Tan, J. Cai, H. Takebayashi, M. Nakafuku, W. Richardson and M. Qiu, Dual origin of spinal oligodendrocyte progenitors and evidence for the cooperative role of Olig2 and Nkx2.2 in the control of oligodendrocyte differentiation, Development 129 (2002), 681-693.

[40] B.P. Fulton, J.F. Burne and M.C. Raff, Visualization of O-2A progenitor cells in developing and adult rat optic nerve by quisqualate-stimulated cobalt uptake, J Neurosci 12 (1992), 4816-4833.

[41] F.H. Gage, Mammalian neural stem cells, Science 287 (2000), 1433-1438

[42] D. Garbossa, M. Fontanella, C. Fronda, C. Benevello, G. Muraca, A. Ducati and A. Vercelli, New strategies for repairing the injured spinal cord: the role of stem cells, Neurol Res $\mathbf{2 8}$ (2006), 500-504.

[43] J.M. Gensert and J.E. Goldman, Heterogeneity of cycling glial progenitors in the adult mammalian cortex and white matter, J Neurobiol 48 (2001), 75-86.

[44] L. Goretzki, M.A. Burg, K.A. Grako and W.B. Stallcup, High-affinity binding of basic fibroblast growth factor and platelet-derived growth factor-AA to the core protein of the NG2 proteoglycan, J Biol Chem 274 (1999), 16831-16837.

[45] V. Graham, J. Khudyakov, P. Ellis and L. Pevny, SOX2 functions to maintain neural progenitor identity, Neuron 39 (2003), 749-765.

[46] S.D. Grossman, L.J. Rosenberg and J.R. Wrathall, Temporalspatial pattern of acute neuronal and glial loss after spinal cord contusion, Exp Neurol 168 (2001), 273-282.

[47] J.D. Guest, E.D. Hiester and R.P. Bunge, Demyelination and Schwann cell responses adjacent to injury epicenter cavities following chronic human spinal cord injury, Exp Neurol 192 (2005), 384-393.

[48] T. Hagg and M. Oudega, Degenerative and spontaneous regenerative processes after spinal cord injury, J Neurotrauma 23 (2006), 264-280.

[49] A. Hall, N.A. Giese and W.D. Richardson, Spinal cord oligodendrocytes develop from ventrally derived progenitor cells that express PDGF alpha-receptors, Development 122 (1996), 4085-4094.

[50] L.L. Horky, F. Galimi, F.H. Gage and P.J. Horner, Fate of endogenous stem/progenitor cells following spinal cord injury, J Comp Neurol 498 (2006), 525-538.

[51] P.J. Horner, A.E. Power, G. Kempermann, H.G. Kuhn, T.D. Palmer, J. Winkler, L.J. Thal and F.H. Gage, Proliferation and differentiation of progenitor cells throughout the intact adult rat spinal cord, J Neurosci 20 (2000), 2218-2228.

[52] P.J. Horner, M. Thallmair and F.H. Gage, Defining the NG2expressing cell of the adult CNS, J Neurocytol 31 (2002), $469-480$.

[53] L.L. Jones, Y. Yamaguchi, W.B. Stallcup and M.H. Tuszyns$\mathrm{ki}, \mathrm{NG} 2$ is a major chondroitin sulfate proteoglycan produced after spinal cord injury and is expressed by macrophages and oligodendrocyte progenitors, J Neurosci 22 (2002), 27922803.

[54] S. Karimi-Abdolrezaee, E. Eftekharpour, J. Wang, C.M. Morshead and M.G. Fehlings, Delayed transplantation of adult neural precursor cells promotes remyelination and functional neurological recovery after spinal cord injury, J Neurosci $\mathbf{2 6}$ (2006), 3377-3389.

[55] Y. Ke, L. Chi, R. Xu, C. Luo, D. Gozal and R. Liu, Early response of endogenous adult neural progenitor cells to acute spinal cord injury in mice, Stem Cells 24 (2006), 1011-1019.

[56] H.S. Keirstead and W.F. Blakemore, The role of oligodendrocytes and oligodendrocyte progenitors in CNS remyelination, Adv Exp Med Biol 468 (1999), 183-197.

[57] H.S. Keirstead, G. Nistor, G. Bernal, M. Totoiu, F. Cloutier, K. Sharp and O. Steward, Human embryonic stem cellderived oligodendrocyte progenitor cell transplants remyelinate and restore locomotion after spinal cord injury, $\mathrm{J} \mathrm{Neu}$ rosci 25 (2005), 4694-4705.

[58] N. Kessaris, M. Fogarty, P. Iannarelli, M. Grist, M. Wegner and W.D. Richardson, Competing waves of oligodendrocytes in the forebrain and postnatal elimination of an embryonic lineage, Nat Neurosci 9 (2006), 173-179.

[59] N. Kessaris, N. Pringle and W.D. Richardson, Ventral neurogenesis and the neuron-glial switch, Neuron 31 (2001), 677-680.

[60] P.L. Kuhn and J.R. Wrathall, A mouse model of graded contusive spinal cord injury, J Neurotrauma 15 (1998), 125-140.

[61] S. Lacroix and M.H. Tuszynski, Neurotrophic factors and gene therapy in spinal cord injury, Neurorehabil Neural Repair 14 (2000), 265-275.

[62] A. Lakatos and R.J. Franklin, Transplant mediated repair of the central nervous system: an imminent solution? Curr Opin Neurol 15 (2002), 701-705.

[63] A.C. Lepore, B. Neuhuber, T.M. Connors, S.S. Han, Y. Liu, M.P. Daniels, M.S. Rao and I. Fischer, Long-term fate of neural precursor cells following transplantation into developing and adult CNS, Neuroscience 142 (2006), 287-304.

[64] J.M. Levine, R. Reynolds and J.W. Fawcett, The oligodendrocyte precursor cell in health and disease, Trends Neurosci 24 (2001), 39-47.

[65] J.M. Levine, F. Stincone and Y.S. Lee, Development and differentiation of glial precursor cells in the rat cerebellum, Glia 7 (1993), 307-321.

[66] X.H. Lin, K. Dahlin-Huppe and W.B. Stallcup, Interaction of the NG2 proteoglycan with the actin cytoskeleton, $J$ Cell Biochem 63 (1996), 463-477.

[67] X.H. Lin, K.A. Grako, M.A. Burg and W.B. Stallcup, NG2 proteoglycan and the actin-binding protein fascin define separate populations of actin-containing filopodia and lamellipodia during cell spreading and migration, Mol Biol Cell 7 (1996), 1977-1993.

[68] Y. Liu and M.S. Rao, Olig genes are expressed in a heterogeneous population of precursor cells in the developing spinal cord, Glia 45 (2004), 67-74.

[69] Y. Liu, Y. Wu, J.C. Lee, H. Xue, L.H. Pevny, Z. Kaprielian and M.S. Rao, Oligodendrocyte and astrocyte development in rodents: an in situ and immunohistological analysis during embryonic development, Glia 40 (2002), 25-43.

[70] J. Lytle, Response of NG2-Expressing Cells to Spinal Cord Contusion: Evidence for the Stimulation of Oligodendrocyte Progenitor Cells (OPCs) and Non-OPC Populations, PhD Dissertation, Georgetown University, 2007.

[71] J.M. Lytle, S. Vicini and J.R. Wrathall, Phenotypic changes in NG2+ cells after spinal cord injury, J Neurotrauma $\mathbf{2 3}$ (2006), 1726-1738.

[72] J.M. Lytle and J.R. Wrathall, Glial cell loss, proliferation and replacement in the contused murine spinal cord, Eur $J$ Neurosci 25 (2007), 1711-1724. 
[73] E. Manser, T. Leung, H. Salihuddin, Z.S. Zhao and L. Lim, A brain serine/threonine protein kinase activated by $\mathrm{Cdc} 42$ and Rac1, Nature 367 (1994), 40-46.

[74] W.B. McKay, D.S. Stokic and M.R. Dimitrijevic, Assessment of corticospinal function in spinal cord injury using transcranial motor cortex stimulation: a review, J Neurotrauma $\mathbf{1 4}$ (1997), 539-548.

[75] D.M. McTigue, P. Wei and B.T. Stokes, Proliferation of NG2positive cells and altered oligodendrocyte numbers in the contused rat spinal cord, J Neurosci 21 (2001), 3392-3400.

[76] R.H. Miller, Regulation of oligodendrocyte development in the vertebrate CNS, Prog Neurobiol 67 (2002), 451-467.

[77] A.J. Mothe and C.H. Tator, Proliferation, migration, and differentiation of endogenous ependymal region stem/progenitor cells following minimal spinal cord injury in the adult rat, Neuroscience 131 (2005), 177-187.

[78] M. Murray and I. Fischer, Transplantation and gene therapy: combined approaches for repair of spinal cord injury, Neuroscientist 7 (2001), 28-41.

[79] T.M. Myckatyn, S.E. Mackinnon and J.W. McDonald, Stem cell transplantation and other novel techniques for promoting recovery from spinal cord injury, Transpl Immunol 12 (2004), 343-358.

[80] J. Namiki and C.H. Tator, Cell proliferation and nestin expression in the ependyma of the adult rat spinal cord after injury, J Neuropathol Exp Neurol 58 (1999), 489-498.

[81] A. Nishiyama, A. Chang and B.D. Trapp, NG2+ glial cells: a novel glial cell population in the adult brain, J Neuropathol Exp Neurol 58 (1999), 1113-1124.

[82] A. Nishiyama, X.H. Lin, N. Giese, C.H. Heldin and W.B. Stallcup, Co-localization of NG2 proteoglycan and PDGF alpha-receptor on $\mathrm{O} 2 \mathrm{~A}$ progenitor cells in the developing rat brain, J Neurosci Res 43 (1996), 299-314.

[83] A. Nishiyama, M. Watanabe, Z. Yang and J. Bu, Identity, distribution, and development of polydendrocytes: NG2expressing glial cells, J Neurocytol 31 (2002), 437-455.

[84] A. Nishiyama, M. Yu, J.A. Drazba and V.K. Tuohy, Normal and reactive $\mathrm{NG} 2+$ glial cells are distinct from resting and activated microglia, J Neurosci Res 48 (1997), 299-312.

[85] C.D. Nobes and A. Hall, Rho, rac and cdc42 GTPases: regulators of actin structures, cell adhesion and motility, Biochem Soc Trans 23 (1995), 456-459.

[86] C.D. Nobes and A. Hall, Rho, rac, and cdc42 GTPases regulate the assembly of multimolecular focal complexes associated with actin stress fibers, lamellipodia, and filopodia, Cell 81 (1995), 53-62.

[87] C.D. Nobes, P. Hawkins, L. Stephens and A. Hall, Activation of the small GTP-binding proteins rho and rac by growth factor receptors, J Cell Sci 108 (Pt 1$)$ (1995), 225-233.

[88] L.J. Noble and J.R. Wrathall, Correlative analyses of lesion development and functional status after graded spinal cord contusive injuries in the rat, Exp Neurol 103 (1989), 34-40.

[89] Y. Ohori, S. Yamamoto, M. Nagao, M. Sugimori, N. Yamamoto, K. Nakamura and M. Nakafuku, Growth factor treatment and genetic manipulation stimulate neurogenesis and oligodendrogenesis by endogenous neural progenitors in the injured adult spinal cord, J Neurosci 26 (2006), 1194811960.

[90] H. Okano, Y. Ogawa, M. Nakamura, S. Kaneko, A. Iwanami and Y. Toyama, Transplantation of neural stem cells into the spinal cord after injury, Semin Cell Dev Biol 14 (2003), 191-198.

[91] W.Y. Ong and J.M. Levine, A light and electron microscopic study of NG2 chondroitin sulfate proteoglycan-positive oligodendrocyte precursor cells in the normal and kainatelesioned rat hippocampus, Neuroscience 92 (1999), 83-95.

[92] D.D. Pearse and M.B. Bunge, Designing cell- and gene-based regeneration strategies to repair the injured spinal cord, $J$ Neurotrauma 23 (2006), 438-452.

[93] L. Pevny and M. Placzek, SOX genes and neural progenitor identity, Curr Opin Neurobiol 15 (2005), 7-13.

[94] W. Plunet, B.K. Kwon and W. Tetzlaff, Promoting axonal regeneration in the central nervous system by enhancing the cell body response to axotomy, J Neurosci Res 68 (2002), 1-6.

[95] Y. Qi, J. Cai, Y. Wu, R. Wu, J. Lee, H. Fu, M. Rao, L. Sussel, J. Rubenstein and M. Qiu, Control of oligodendrocyte differentiation by the $\mathrm{Nkx} 2.2$ homeodomain transcription factor, Development 128 (2001), 2723-2733.

[96] A.G. Rabchevsky, P.G. Sullivan and S.W. Scheff, Temporalspatial dynamics in oligodendrocyte and glial progenitor cell numbers throughout ventrolateral white matter following contusion spinal cord injury, Glia 55 (2007), 831-843.

[97] M.C. Raff, R.H. Miller and M. Noble, A glial progenitor cell that develops in vitro into an astrocyte or an oligodendrocyte depending on culture medium, Nature 303 (1983), 390-396.

[98] C.S. Raine, G.R. Moore, R. Hintzen and U. Traugott, Induction of oligodendrocyte proliferation and remyelination after chronic demyelination. Relevance to multiple sclerosis, $L a b$ Invest 59 (1988), 467-476.

[99] P.J. Reier, Cellular transplantation strategies for spinal cord injury and translational neurobiology, NeuroRx 1 (2004), 424-451.

[100] R. Reynolds and R. Hardy, Oligodendroglial progenitors labeled with the $\mathrm{O} 4$ antibody persist in the adult rat cerebral cortex in vivo, J Neurosci Res 47 (1997), 455-470.

[101] A.J. Ridley, H.F. Paterson, C.L. Johnston, D. Diekmann and A. Hall, The small GTP-binding protein rac regulates growth factor-induced membrane ruffling, Cell 70 (1992), 401-410.

[102] L.J. Rosenberg, Y.D. Teng and J.R. Wrathall, 2,3-Dihydroxy6-nitro-7-sulfamoyl-benzo(f)quinoxaline reduces glial loss and acute white matter pathology after experimental spinal cord contusion, J Neurosci, 19 (1999), 464-475.

[103] L.J. Rosenberg, L.J. Zai and J.R. Wrathall, Chronic alterations in the cellular composition of spinal cord white matter following contusion injury, Glia 49 (2005), 107-120.

[104] T. Seki, K. Hida, M. Tada, I. Koyanagi and Y. Iwasaki, Graded contusion model of the mouse spinal cord using a pneumatic impact device, Neurosurgery 50 (2002), 1075-1081; discussion 1081-1072.

[105] M.A. Sells, J.T. Boyd and J. Chernoff, p21-activated kinase 1 (Pak1) regulates cell motility in mammalian fibroblasts, $J$ Cell Biol 145 (1999), 837-849.

[106] J. Sohn, J. Natale, L.J. Chew, S. Belachew, Y. Cheng, A. Aguirre, J. Lytle, B. Nait-Oumesmar, C. Kerninon, M. KanaiAzuma, Y. Kanai and V. Gallo, Identification of Sox17 as a transcription factor that regulates oligodendrocyte development, J Neurosci 26 (2006), 9722-9735.

[107] I. Sommer and M. Schachner, Cell that are O4 antigenpositive and $\mathrm{O} 1$ antigen-negative differentiate into $\mathrm{O} 1$ antigen-positive oligodendrocytes, Neurosci Lett 29 (1982), $183-188$.

[108] J.M. Sroga, T.B. Jones, K.A. Kigerl, V.M. McGaughy and P.G. Popovich, Rats and mice exhibit distinct inflammatory reactions after spinal cord injury, J Comp Neurol 462 (2003), 223-240.

[109] W.B. Stallcup, The NG2 proteoglycan: past insights and future prospects, J Neurocytol 31 (2002), 423-435. 
[110] M. Takahashi, Y. Arai, H. Kurosawa, N. Sueyoshi and S. Shirai, Ependymal cell reactions in spinal cord segments after compression injury in adult rat, $J$ Neuropathol Exp Neurol 62 (2003), 185-194.

[111] H. Takebayashi, Y. Nabeshima, S. Yoshida, O. Chisaka and $\mathrm{K}$. Ikenaka, The basic helix-loop-helix factor olig2 is essential for the development of motoneuron and oligodendrocyte lineages, Curr Biol 12 (2002), 1157-163.

[112] H. Takebayashi, S. Yoshida, M. Sugimori, H. Kosako, R. Kominami, M. Nakafuku and Y. Nabeshima, Dynamic expression of basic helix-loop-helix Olig family members: implication of Olig2 in neuron and oligodendrocyte differentiation and identification of a new member, Olig3, Mech Dev 99 (2000), 143-148.

[113] C.H. Tator, Experimental circumferential compression injury of primate spinal cord, Proc Veterans Adm Spinal Cord Inj Conf 18 (1971), 2-5.

[114] S. Temple and A. Alvarez-Buylla, Stem cells in the adult mammalian central nervous system, Curr Opin Neurobiol 9 (1999), 135-141.

[115] N. Terada, K. Baracskay, M. Kinter, S. Melrose, P.J. Brophy, C. Boucheix, C. Bjartmar, G. Kidd and B.D. Trapp, The tetraspanin protein, CD9, is expressed by progenitor cells committed to oligodendrogenesis and is linked to beta1 integrin, CD81, and Tspan-2, Glia 40 (2002), 350-359.

[116] A. Tessler, Intraspinal transplants, Ann Neurol 29 (1991), 115-123.

[117] M.O. Totoiu and H.S. Keirstead, Spinal cord injury is accompanied by chronic progressive demyelination, J Comp Neurol 486 (2005), 373-383.

[118] J. Trotter and M. Schachner, Cells positive for the O4 surface antigen isolated by cell sorting are able to differentiate into astrocytes or oligodendrocytes, Brain Res Dev Brain Res 46 (1989), 115-122.

[119] E.M. Ullian, S.K. Sapperstein, K.S. Christopherson and B.A. Barres, Control of synapse number by glia, Science 291 (2001), 657-661.

[120] A. Vallstedt, J.M. Klos and J. Ericson, Multiple dorsoventral origins of oligodendrocyte generation in the spinal cord and hindbrain, Neuron 45 (2005), 55-67.

[121] S. Weiss, C. Dunne, J. Hewson, C. Wohl, M. Wheatley, A.C. Peterson and B.A. Reynolds, Multipotent CNS stem cells are present in the adult mammalian spinal cord and ventricular neuroaxis, J Neurosci 16 (1996), 7599-7609.

[122] G. Wolswijk and M. Noble, Identification of an adult-specific glial progenitor cell, Development 105 (1989), 387-400.

[123] J.R. Wrathall, D. Choiniere and Y.D. Teng, Dose-dependent reduction of tissue loss and functional impairment after spinal cord trauma with the AMPA/kainate antagonist NBQX, $J$ Neurosci 14 (1994), 6598-6607.

[124] J.R. Wrathall, W. Li and L.D. Hudson, Myelin gene expression after experimental contusive spinal cord injury, $\mathrm{J} \mathrm{Neu}$ rosci 18 (1998), 8780-8793.

[125] X. Xu, J. Cai, H. Fu, R. Wu, Y. Qi, G. Modderman, R. Liu and M. Qiu, Selective expression of Nkx-2.2 transcription factor in chicken oligodendrocyte progenitors and implications for the embryonic origin of oligodendrocytes, Mol Cell Neurosci 16 (2000), 740-753.

[126] H. Yang, P. Lu, H.M. McKay, T. Bernot, H. Keirstead, O. Steward, F.H. Gage, V.R. Edgerton and M.H. Tuszynski, Endogenous neurogenesis replaces oligodendrocytes and astrocytes after primate spinal cord injury, J Neurosci 26 (2006), 2157-2166.

[127] S. Yoo and J.R. Wrathall, Mixed primary culture and clonal analysis provide evidence that NG2 proteoglycan-expressing cells after spinal cord injury are glial progenitors, $\mathrm{Dev} \mathrm{Neu}$ robiol 67 (2007), 860-874.

[128] X. Yuan, R. Chittajallu, S. Belachew, S. Anderson, C.J. McBain and V. Gallo, Expression of the green fluorescent protein in the oligodendrocyte lineage: a transgenic mouse for developmental and physiological studies, J Neurosci Res, 70 (2002), 529-545.

[129] T. Yue, K. Xian, E. Hurlock, M. Xin, S.G. Kernie, L.F. Parada and Q.R. Lu, A critical role for dorsal progenitors in cortical myelination, J Neurosci 26 (2006), 1275-1280.

[130] L.J.Zai and J.R. Wrathall, Cell proliferation and replacement following contusive spinal cord injury, Glia 50 (2005), 247257.

[131] Q. Zhou and D.J. Anderson, The bHLH transcription factors OLIG2 and OLIG1 couple neuronal and glial subtype specification, Cell 109 (2002), 61-73.

[132] Q. Zhou, G. Choi and D.J. Anderson, The bHLH transcription factor Olig2 promotes oligodendrocyte differentiation in collaboration with Nkx2.2, Neuron 31 (2001), 791-807.

[133] Q. Zhou, S. Wang and D.J. Anderson, Identification of a novel family of oligodendrocyte lineage-specific basic helixloop-helix transcription factors, Neuron 25 (2000), 331-343.

[134] T. Zigova, V. Pencea, R. Betarbet, S.J. Wiegand, C. Alexander, R.A. Bakay and M.B. Luskin, Neuronal progenitor cells of the neonatal subventricular zone differentiate and disperse following transplantation into the adult rat striatum, Cell Transplant 7 (1998), 137-156.

[135] E.A. Zompa, L.D. Cain, A.W. Everhart, M.P. Moyer and C.E. Hulsebosch, Transplant therapy: recovery of function after spinal cord injury, J Neurotrauma 14 (1997), 479-506. 


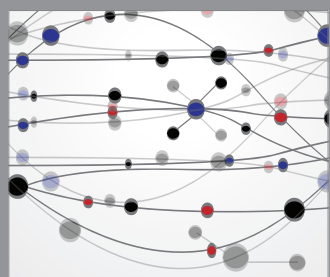

The Scientific World Journal
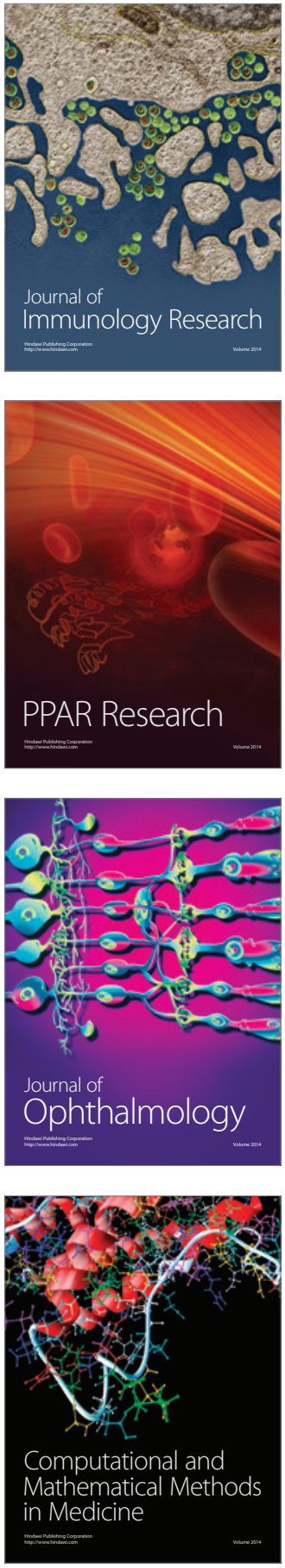

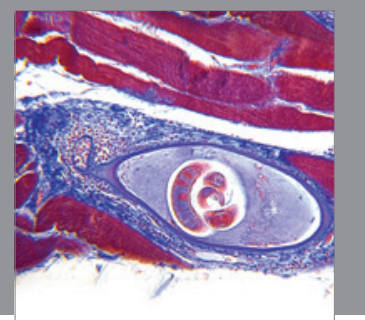

Gastroenterology

Research and Practice
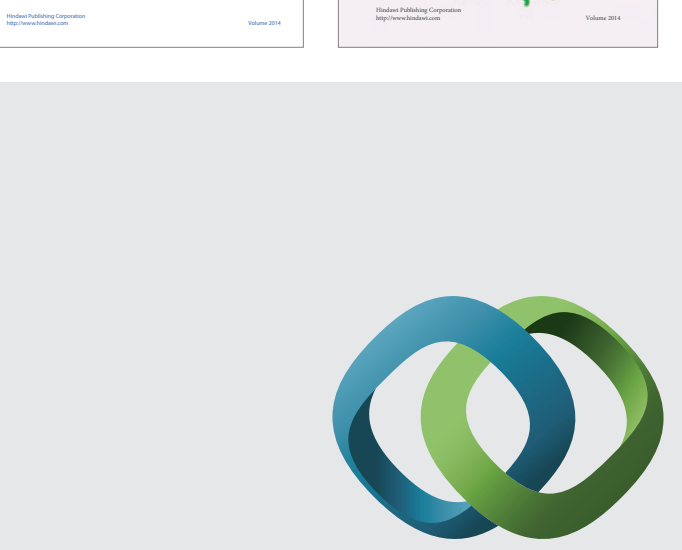

\section{Hindawi}

Submit your manuscripts at

http://www.hindawi.com
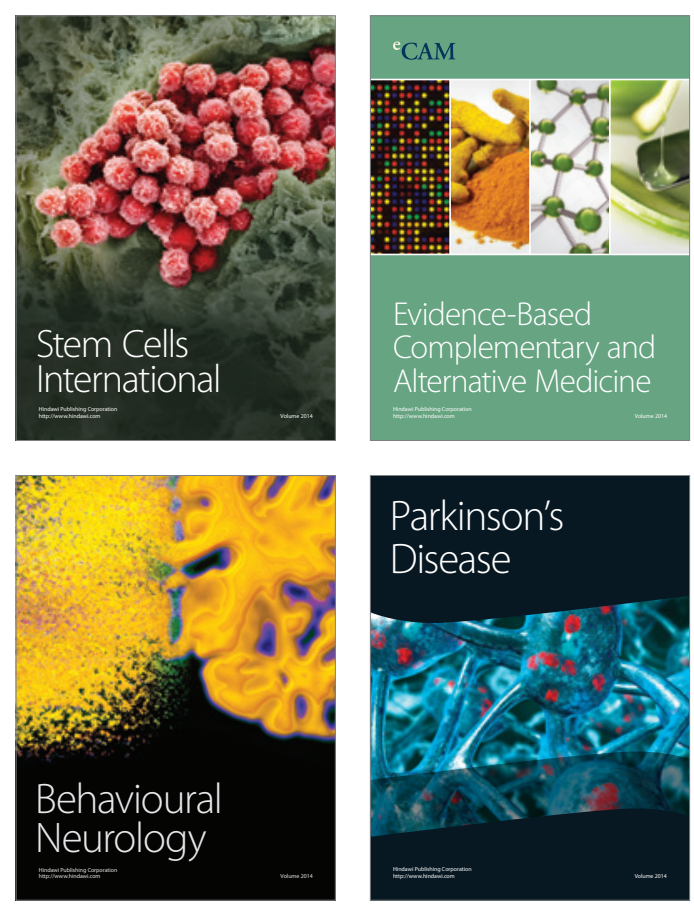

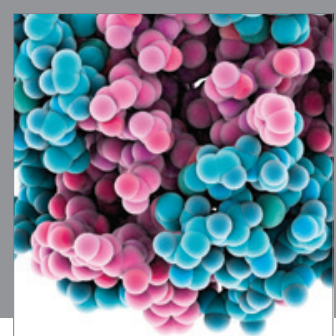

Journal of
Diabetes Research

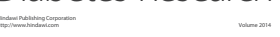

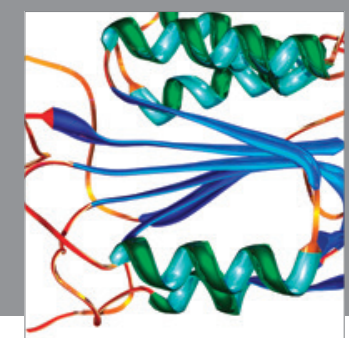

Disease Markers
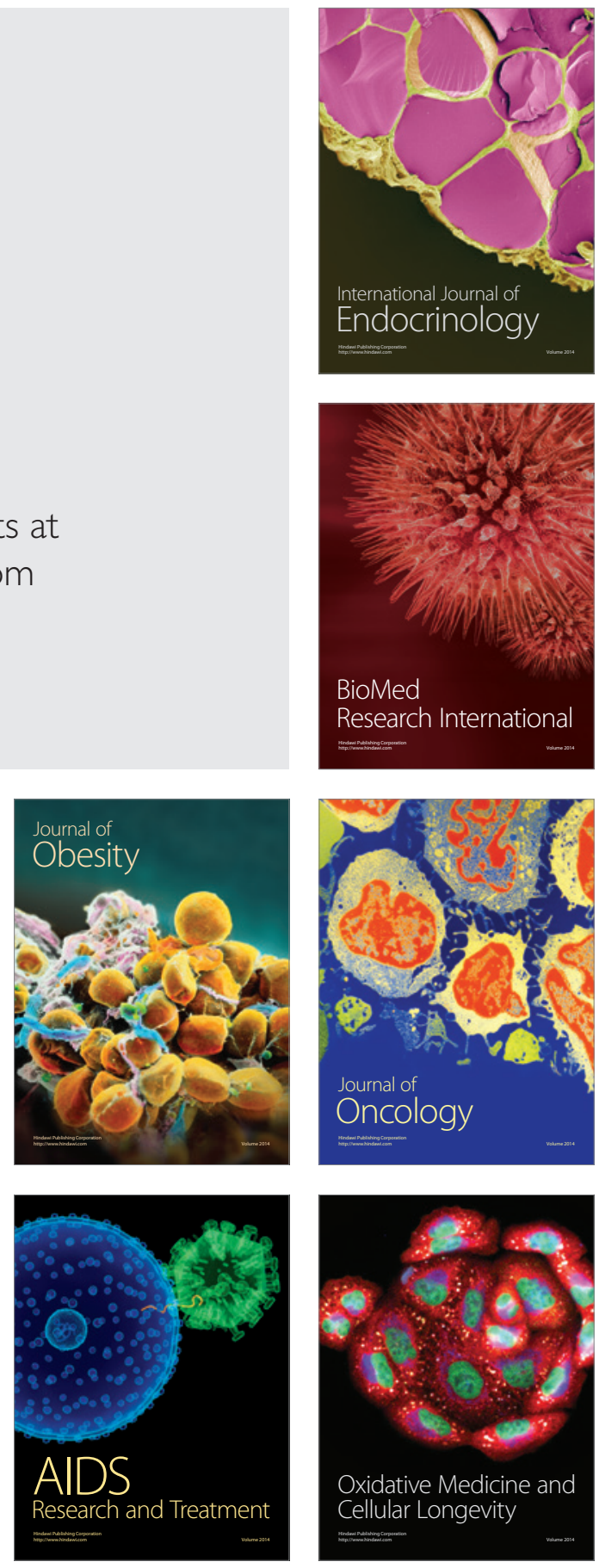